\title{
Patients and Their Daily Life
}

\section{INTRODUCTION}

When asylums were converted to war hospitals, scenes of departure of their civilian patients captured some sense of the asylum as a community. " Many patients lost their "home", and staff and other patients with whom they had supportive relationships. Dr. Thompson, a medical superintendent, wrote:

The scenes on departure aroused varying emotions in myself, my medical colleagues, and the nurses. It was all interesting, some of it most amusing, and much sadly pathetic....[T] he whole gamut of emotion was exhibited by the patients on leaving, ranging from acute distress and misery, through gay indifference, to maniacal fury and indignation.... I did not realise the strong mutual attachment till it was severed. ${ }^{2}$

Marriott Cooke and Hubert Bond, in their History of the Asylum War Hospitals, also acknowledged the distress of departures, for both patients and staff. ${ }^{3}$ The asylums were by no means ideal, and the dependence which asylums created for their patients probably contributed to their sense of loss, but meaningful human relationships still existed within them.

The day Britain declared war against Germany, the Board of Control ("the Board") was inspecting Oxford Asylum. Patients were restless on

C. Hilton, Civilian Lunatic Asylums During the First World War, Mental Health in Historical Perspective, https://doi.org/10.1007/978-3-030-54871-1_6 
one overcrowded and understaffed ward, but the inspectors complimented the asylum because most patients were calm and the wards peaceful. ${ }^{4}$ The inspectors interpreted their observations as indicating that patients were "evidently very well treated" and their insanities well managed. ${ }^{5}$ The Board recognised that personal dignity and providing appropriate employment, social diversions and as much freedom as possible could alleviate patients' distress, lessen untoward behaviours and enhance wellbeing. ${ }^{6}$ However, it appeared less aware of the damaging effects of institutional living or that a bullying or oppressive regime could produce apathetic and subdued patients. These only became widely acknowledged several decades later. In the 1950s, psychiatrist Russell Barton, working in England, regarded the quiet and submissive state of many mental hospital patients almost as an illness in its own right. He termed it "institutional neurosis". Others used the terms "prison stupor", "prison psychosis", "institutionalism" or "institutionalisation". 7 Erving Goffman in his ethnographic study of an asylum in the United States of America (USA), also in the 1950s, identified many of the mechanisms by which patients were institutionalised, beginning with admission processes which forced "role dispossession" and "curtailment of self" relative to life outside. ${ }^{8}$

The Board did not have recourse to uniform criteria to set and monitor healthcare standards of the sort which began to emerge in the USA in the 1930s. ${ }^{9}$ The Board set its own standards, based on experience of what it knew could be achieved and ideals expressed by colleagues, such as those which psychiatrist Charles Mercier incorporated into his textbooks. ${ }^{10}$ Disconcertingly, Mercier's books were published almost 20 years before the war, and two decades of relative prosperity failed to achieve many of the recommendations. In addition to comparing asylum standards to ideals stated by psychiatrists or to workhouse and domestic norms, wartime comparators included care considered acceptable for soldiers. In contrast to the minimal public attention paid to care for civilian "pauper lunatics", there was widespread concern about the necessity to provide dignified care for shell shocked men who had served their country.

When the Board recognised conditions which it deemed detrimental to patients, it encouraged the asylum management "visiting" committee (VC) to remedy them. ${ }^{11}$ Despite this, and the asylums running according to tight rules, different standards of care were experienced from patient to patient, ward to ward and asylum to asylum. There was no such thing as an average ward, but we can still attempt to understand something of the 
daily life of patients who spent days, or years, in them. In earlier chapters we discussed how the asylum system worked, the nature of the patients' mental disorders and their treatments, and issues around staffing and the provision and distribution of food and fuel, all of which underpinned and influenced daily life. In this chapter exploring facets of daily life, we begin by considering sources which reveal something of the patients' perspectives. We then move onto some specific aspects of their lives: clothing; cleanliness and provision of basic amenities; night times; links with the outside world; and the asylum work which they undertook.

\section{Seeking the Patients' View}

To understand patients' experiences, it is best to use sources which they created. Some wrote memoirs about their admissions. Mary Riggall, Rachel Grant-Smith and James Scott described their experiences in England; D Davidson wrote about his experience in England and Australia; and Clifford Beers about his in the USA. ${ }^{12}$ They wrote their reminiscences months or years after discharge. Time for reflection, and their intention to inform the public about mental illness and to encourage improvements in prevention, care and treatment could have influenced their content and style. ${ }^{13}$ Despite being situated on several continents before, during and after the war, their asylum experiences suggest that institutional psychiatric treatment and care across the English-speaking Western world had many commonalities. Their descriptions, when combined with those from more patients, such as in committee minutes and the Cobb Inquiry triggered by Montagu Lomax's book, ${ }^{14}$ give a range of bottom-up, personal perspectives. All need careful interpretation: official minutes, for example, may be biased against a patient's testimony.

The value of patient-derived written sources is particularly important as senior asylum personnel and the institutions' inspectors largely ignored the patients' words. The Lunacy Act 1890 stipulated that asylum inspectors must "see" every patient, and "give everyone, as far as possible, full opportunity of complaint". ${ }^{15}$ The Board interpreted this literally, probably a necessity during a typical two-day inspection of a large asylum. If inspectors entered a ward with patients and staff gathered, they could "see" everyone, and could then ask the group if anyone wanted to speak to them, thus giving them the "opportunity". It would be a brave patient 
to indicate that he or she wanted to make a complaint. If staff accompanied inspectors on their rounds, a patient might not be permitted to speak with one in confidence. Also, if a staff member offered an alternative perspective, staff words usually had primacy over those of patients. ${ }^{16}$

The Board inspectors handed their written report to the asylum leadership at the end of their inspection and intended to publish it in their own annual report. The published narratives informed the public of standards expected, what was found, and the advice given to make improvements. Inspection reports for 1914 mentioned complaints from patients, but they were often trivialised: "We had but few complaints, and none of a serious character", or they were "evidently based on a delusional condition of mind", or were not "worthy of mention", or "we did not receive any complaints... which had any foundation of fact". 17 The rapidly written reports would have allowed little time for anything other than cursory discussion of complaints with senior asylum staff who tended to offer reassuring explanations, with the Board concluding that complaints required no further attention. Generalisations about patients' complaints were compatible with psychiatric opinion which regarded insanity as all-encompassing: patients needed guidance and supervision in all matters and their interpretation of events was distorted by their mental state. ${ }^{18}$ Inconsistently, however, these assumptions disappeared if a patient complimented the leadership or made comments with which they agreed. ${ }^{19}$ Positive comments were acknowledged at face value, despite the illogicality of accepting one sort of comment while automatically rejecting another. Allegations from patients of ephemeral, unprovable occurrences, such as dietary inadequacies or staff rough handling them, were particularly likely not to be believed by a self-assured, defensive leadership which assumed that staff behaved kindly and appropriately and patients were untrustworthy.

Neglecting complaints on the basis of a patient's mental disorder was a recurring grievance expressed in memoirs. Grant-Smith reflected: "Once tainted with a certificate of madness, every statement made by the so-called lunatic can be characterised as a further sign of his or her unsoundness of mind." 20 When she complained, the authorities transferred her to another asylum ${ }^{21}$ : it was easier to move a so-called troublemaker than to deal with their concerns. ${ }^{22}$ When she wrote to the Lord Chancellor (her right under the Lunacy Act), he replied two days later, stating that he had made inquiries into her complaints and "sees no reason for thinking they are well founded". No one had discussed her 
complaints with her during that time and she found it hard to believe that such speedy inquiries were meaningful. ${ }^{23}$ The impression given was that she was fobbed off.

Despite questioning the validity of patients' opinions, the Board expected VCs to listen to their patients, although VCs tended to follow the Board's example rather than its advice. ${ }^{24}$ The Cobb Inquiry took evidence from patients but rationalised that they would only want to speak if they were aggrieved at their experience, about which their memories would inevitably be distorted because of their mental state. Otherwise, if happy with the treatment they received, they would want to avoid the risk of inquiry-related publicity about them ever having suffered from a mental disorder which required certification. ${ }^{25}$ Thus, preconceived ideas affected the analysis of the inquiry's evidence, with negative accounts from patients documented in the transcript, but overlooked in writing the inquiry report. Similar happened at the Royal Commission on Lunacy (1924-1926) which followed the Cobb Inquiry. ${ }^{26}$

Patients continued to complain, despite their words being rejected. One woman, Elizabeth T, an in-patient for over 20 years, transferred to Claybury from Horton when it became a war hospital in 1915, alleged that staff stole some of her money and belongings. Her doctor explained away the allegations, saying that she was "subject to frequent lapses and loses her property, and as it is necessary to prevent her from collecting rubbish, she imagines her money is taken". His analysis meant that allegations of theft could be overlooked, protecting his colleagues, but if Elizabeth was correct, in effect he was condoning criminal activity. The doctor also did not acknowledge that his perception of rubbish might have included objects meaningful to Elizabeth. ${ }^{27}$ As Goffman explained, in an institution where everyone was stripped of their possessions on admission, they were also stripped of their personal identity, so that when a patient

fills his pockets with bits of string and rolled up paper, and when he fights to keep these possessions in spite of the consequent inconvenience to those who must regularly go through his pockets, he is usually seen as engaging in symptomatic behaviour befitting a very sick patient, not as someone who is attempting to stand apart from the place accorded him. ${ }^{28}$

Rather than talking to patients, inspectors focussed on the asylum environment, activities they witnessed, ledgers of standardised forms, and 
reports from VC members and a few senior staff. This was less taxing, time consuming and conflict-laden than speaking to patients. Similarly, in the absence of the patient's voice, Diane Carpenter, historian of asylums in Hampshire before 1914, based her study on objectively quantifiable material commodities as proxy indicators of standards. ${ }^{29}$ When she compared them to domestic dwellings and workhouses, she found that the asylums' basic provision was relatively satisfactory. Asylum cleanliness and personal hygiene, for example, usually compared favourably with other living environments, and clothes, though institutional, provided warmth and were of good quality. Carpenter concluded that "In every respect improvements occurred as time progressed." 30 As we shall see in this chapter, standards varied, and when wartime priorities engulfed the country, with resources diverted away from civilian needs, especially from people considered a burden on public funds, any pre-war improvements did not continue.

\section{In-Patient Life}

Mary Riggall expressed her feelings about being admitted to an asylum in 1918 and being confined there for 18 months: "It seems to me that Liberty is one of the best things in the world - Liberty in the truest sense of the word, I mean, and not licence." ${ }^{31}$ As with other aspects of asylum life, the Lunacy Act underpinned decisions about freedom for patients, but it did not define if "asylum" meant the ward, the buildings or the entire estate within the perimeter wall. The VCs tended to interpret it narrowly, but the Board regarded confining patients to the wards and their adjacent "airing courts" as unacceptable, unless they were physically unwell. ${ }^{32}$ Psychiatrist Bernard Hollander, took a stronger line: he described locked doors as "a torture", and deprivation of liberty for less ill patients as "cruel and uncalled for." 33 Mercier cautioned staff to be ever vigilant about their patients to avoid catastrophe, ${ }^{34}$ but also considered the blanket restrictions on patient's liberty as overly stringent and devoid of attention to individual need. ${ }^{35}$ It was particularly difficult to achieve a balance of freedoms based on individual need with reduced staff levels and expertise during wartime.

The Board advocated for patients to have as "normal" a life as possible. Wards needed to be pleasant and homely, with "plants, birds and flowers" and pictures on the walls, with their frames made in the asylum workshops. ${ }^{36}$ Wards with the most disturbed patients needed the same recreational facilities as those with calmer patients, even if items might 
be damaged. ${ }^{37}$ The Board emphasised that equipment such as pianos, billiard tables and bagatelle boards should be well maintained, and that staff should "be ready to start a game, such as skittles, quoits, bowls or badminton, and when it is started, to yield his place in it to a patient, and go on with some other duty". 38 The Board expected wards to be "well supplied with books and bound periodicals", including some suitable for "demented patients" and for patients of lower intellectual ability, so all can "be improved and ameliorated". ${ }^{39}$ Books on the wards required changing regularly and were never to be kept in locked book cases. ${ }^{40}$ One asylum subscribed to a braille lending library for a blind patient. ${ }^{41}$ Asylums purchased newspapers and magazines to suit diverse interests, although good intentions fell foul to war time austerity and rising prices when many "half-penny dailies" became "penny dailies". 42 Staff were directed to read newspapers to patients, if required, and ensure that papers were neither monopolised by a few nor destroyed by those with destructive tendencies. ${ }^{43}$

Life was influenced by rules and expectations about gender segregation. Separate gender spheres reflected societal attitudes that women were best equipped for private or domestic realms, while men were naturally suited to active, aggressive and intellectual domains of public life. ${ }^{44}$ Lives of most women were constrained by reproduction and domestic duties, gendered educational opportunities, workplaces and types of employment. Outside asylums, respectable young unmarried women were chaperoned during social encounters with men. As middle-class Vera Brittain wrote in her wartime autobiography, it was "considered correct and inevitable that my aunt should cling to me like a limpet throughout the precious hours" that she spent with her special male friend. ${ }^{45}$ In asylums, the Lunacy Act forbade male staff having responsibility for female patients, ${ }^{46}$ and the architecture reinforced gender segregation, typically separating men from women, both staff and patients, on either side of a central administration block.

Both inside and outside the asylums, a perceived vulnerability of women imposed greater restrictions on their activities compared to those of men. Riggall envied the male patients their cricket matches and long walks. ${ }^{47}$ Trustworthy male patients might be accorded parole within or outside the grounds, a privilege usually beneficial and seldom abused. ${ }^{48}$ Male and female patients were not usually allowed to be together in the asylum's designated patients' gardens (Fig. 6.1) as trees and wellmatured shrubs created "risk in the opportunities afforded for the mixing 


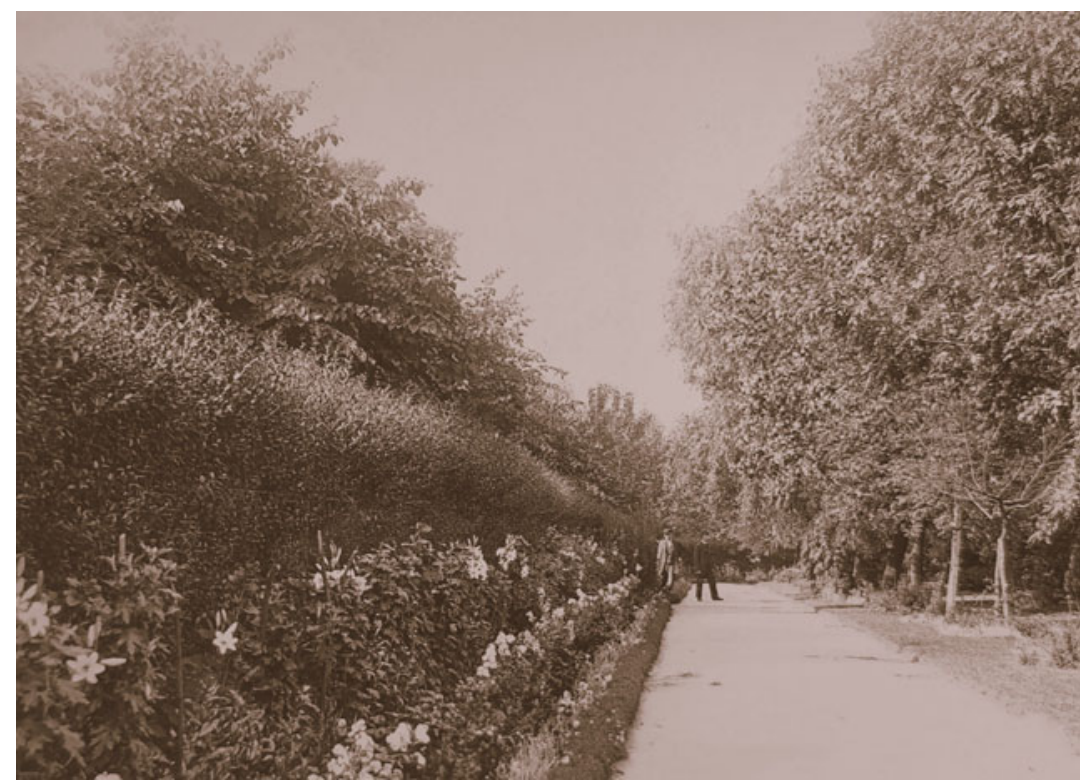

Fig. 6.1 Patients' garden at Claybury, before 1917 (Armstrong-Jones collection, Royal College of Psychiatrists' Archives)

of the sexes". ${ }^{49}$ Occasionally a sexual assault occurred, but those reported in minutes identified staff as perpetrators, not patients. One male staff member was sentenced to six months hard labour for a sexual assault on a woman patient. ${ }^{50}$ This sort of offence reinforced the asylum authorities' determination to "prevent the association of the sexes" except under "complete and careful supervision". 51

As Riggall found, options for physical exercise differed for male and female patients. Some gender segregated outdoor exercise was feasible in each ward's airing court. An ideal airing court was about one acre ( $3 / 4$ of a football pitch) for a ward of 50 patients, properly laid out as a garden, not asphalted or paved, and not like a "bear pit", as one low lying airing court at Hanwell was known. ${ }^{52}$ Wire fences with evergreen shrubs were attractive and therefore preferable to a high wall. ${ }^{53}$ Elsewhere on the estate, accompanied walks for the men provided fresh air and were convenient for staff, with just a few of them required to observe many 
patients. After a patient escaped from a group of 90 accompanied by five staff on a "boundary walk" at Claybury, the VC grudgingly listened to the patients who disliked these large group walks, and proposed a maximum of 50 patients accompanied by five staff. ${ }^{54}$ We are not privy to know whether that satisfied the patients or achieved the VC's goals of preventing escapes, but 50 was still an enormous group for a walk. Such groups may have provided physical exercise, but hardly contributed to a therapeutic staff-patient relationship.

Since asylum activities were part of treatment, Mercier cautioned against punishing patients by preventing them from joining in, as participant, performer or spectator. ${ }^{55}$ On the other hand, activities were used as rewards, such as tram outings to Uxbridge for working patients at Hanwell (Fig. 6.2). ${ }^{56}$ Entertainment programmes continued as usual in the early months of the war, including the annual patients' fancy dress ball at Claybury and a Vaudeville show at Colney Hatch. By Christmas 1914, celebrations faced disruption because of night-time lighting restrictions and risk of cancelation at short notice in the event of an air raid

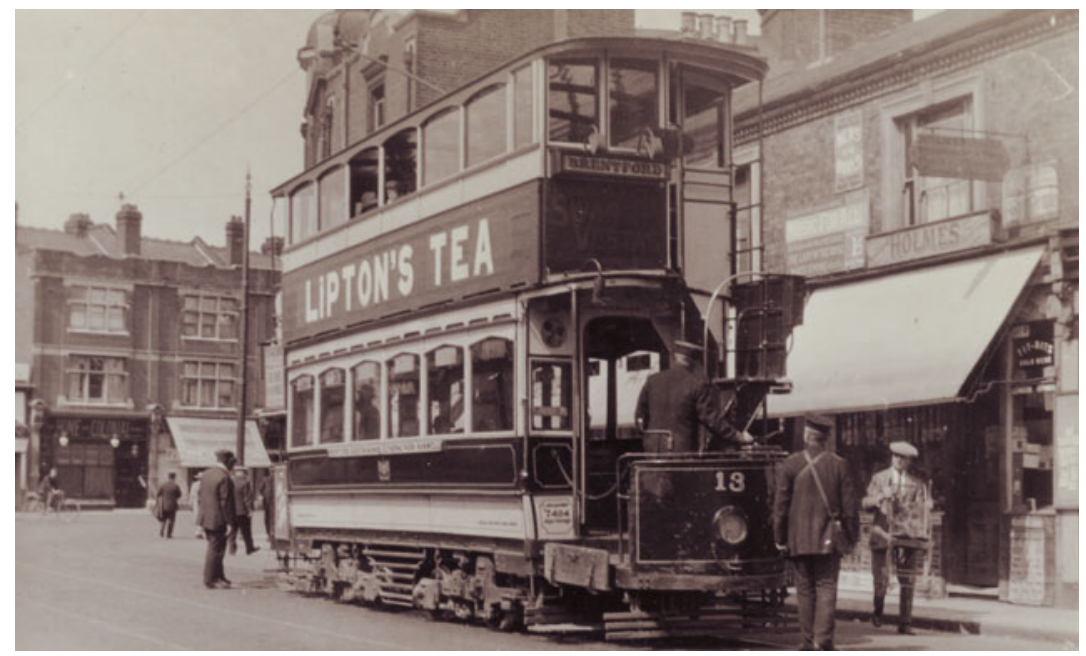

Fig. 6.2 Tram, a few minutes' walk from Hanwell Asylum c.1910 (Public domain), https://en.wikipedia.org/wiki/Hanwell\#/media/File:Tram_in_hanw ell_boston_road.JPG 
warning. ${ }^{57}$ Social events declined further as the war progressed. Cricket matches were curtailed at asylums where pitches were ploughed or used for billeting troops. ${ }^{58}$ If a pitch was available, a diminished workforce precluded staff from working with patients to prepare it and to provide a team, and match refreshments were considered an unnecessary luxury. ${ }^{59}$ Other out-door events, which allowed staff, patients, their relatives and local people to mix and glimpse a display of positive features of asylum life, such as the annual fete, were curtailed by austerity: Claybury budgeted $£ 80$ for a fete pre-war and $£ 10$ during it. ${ }^{60}$ At Colney Hatch, special grants for events and entertainments ceased for the duration of the war. ${ }^{61}$

Spiritual as well as social needs needed to be attended to. The Lunacy Act stipulated that each asylum employ a Church of England chaplain. ${ }^{62}$ Riggall described that she did not go to the laundry to iron on Sundays. ${ }^{63}$ Instead, she went twice to the church in the asylum grounds, where she enjoyed the organ, the singing and "orderly services". Male patients sat on the right with the attendants, and women on the left with the nurses. She compared patients to St. Peter in prison:

I said, one day, to a companion, "Prayer was made for St Peter when he was in prison, and God sent an angel and delivered him - therefore it seems to me that we had better pray that we may recover and be allowed to go home." So two other women and myself used to meet in a quiet corner of the grounds for prayer. And who will dare to say we were not helped and blessed by doing so. ${ }^{64}$

The Lunacy Act also advised that appropriate ministers of religion should be available to visit patients of different denominations and faiths. ${ }^{65}$ Colney Hatch admitted many patients from the East End of London which had a large immigrant Jewish community and for whom it made suitable arrangements. The asylum had a supply of skull caps for the men. ${ }^{66}$ There was a kosher kitchen. ${ }^{67}$ Special arrangements were made for fasts such as the Day of Atonement ${ }^{68}$ and for festivals. Just before the war, 241 patients attended a Passover "seder" service and meal with the visiting chaplain, Reverend Solomon Lipson, who provided the additional, special foods for the ceremony. ${ }^{69}$ During the war, kosher meat was prohibitively expensive ${ }^{70}$ so Lipson advised on dietary changes, with the asylum eventually substituting fish and haricot beans for meat. ${ }^{71}$ If Jewish patients had limited knowledge of English, they were placed on wards 
with other Yiddish speakers. ${ }^{72}$ The asylum also organised interpreters for these patients and for others, through the relevant community, or by a staff member who received a salary supplement for his services, or on an ad hoc basis. ${ }^{73}$

The London County Council (LCC) encouraged admission to Colney Hatch of people belonging to various minority groups, as, based on their experience of catering for the Jewish community, it deemed the asylum's arrangements for "foreigners" better than elsewhere. ${ }^{74}$ Thus, alongside civilian patients who normally resided in the London area and "service" patients, Belgian refugees, prisoners of war and interned enemy aliens were admitted, sometimes transferred from as far afield as Scotland or the Isle of Man. ${ }^{75}$

Over 200,000 Belgian refugees who had fled "the rape of Belgium", the German army advance through their country, arrived in England in the first months of the war. Many were initially taken to one of the British government's largest refugee reception centres, Alexandra Palace, in Hornsey, ${ }^{76}$ two miles from Colney Hatch, before being dispersed throughout the country. Some required asylum admission, either directly from the reception centre or after being housed further afield. If refugee lunatics or their families wished, they could opt to be admitted directly to, or transferred to, Colney Hatch where they had access to an interpreter and they "could be amongst patients who would be able to converse with them and also be visited by their country people". ${ }^{77}$ The asylum authorities worked closely with voluntary committees to support the refugees. ${ }^{78}$ Occasionally, "foreigners" caused concern to civilian patients, such as one who believed he would be harmed by "Germans". It is unclear whether that was part of his psychiatric disorder, but the VC approved his wife's request to transfer him to another asylum. ${ }^{79}$ Colney Hatch minutes recorded little about how the new groups of patients were distributed within the asylum, or how they interacted, suggesting that the social diversity was harmonious. The Board's annual reports raised no concerns. $^{80}$

\section{Clothing}

Exchange of a patient's own clothes for institutional garments, alongside relinquishing most personal possessions, was part of the asylum admission process. This was problematic as clothing and grooming tools, in Goffman's words, are part of an individual's “'identity kit' for the management 
of his personal front" ${ }^{81}$ Removing personal identity was convenient for the institution as it could help ensure patients' compliance with the regime and simplify the organisation of batch-living. In addition, uniformity meant that the leadership could achieve a neat and tidy appearance of their patients as a whole, propagating an image of enlightened care. ${ }^{82}$ This contrasted with the patients' view about asylum clothes. According to Lomax:

Few things are more deeply resented by the ordinary pauper lunatic and his friends than the depriving him of his own clothes, and the compulsory wearing of what he and they regard as "prison" attire. ${ }^{83}$

Asylum clothes differed from both prison attire and workhouse uniforms, but they were institutional, rarely met recommendations about variety, and had little "regard to appearance". ${ }^{84}$ Lomax concurred with the patients and explained that asylum clothing destroyed self-respect, intensified stigma, and gave the impression that admission to an asylum was a crime and disgrace, contributing to patients and their families trying to avoid seeking treatment until late stages of illness. ${ }^{85}$ Jane Hamlett and Lesley Hoskins, in their study of asylum clothing, agreed with Lomax's understanding, but they also argued that despite uniformity or standardization within each asylum, there was no "uniform" as such, and although the clothes identified those who wore them as institutionalized pauper lunatics, clothing was not deliberately used to shame or punish patients or to represent or develop identification with the institution. ${ }^{86}$ Hamlett and Hoskins also argued that by the early twentieth-century the provision of standardized apparel was increasingly criticized and representations were made (though not generally adopted) that patients should be allowed to wear their own clothes. ${ }^{87}$

The Board preferred some variety in attire for both for men and women, such as men's caps being provided in various shapes and colours. ${ }^{88}$ Asylum clothing appeared more uniform if a particular style, fabric or colour became identified with a specific ward. This was convenient and practical, particularly for laundry staff, and ease for staff carried greater weight than choice for patients. ${ }^{89}$ Similarly, for staff convenience, women patients in some asylums had uniform short haircuts, even though in the community women tended to wear their hair long, often plaited or pinned in place. Although Mercier advised only to cut women's hair short "for medical reasons", and the Board criticised asylums where short hair 
for women was commonplace, staff priorities overruled patient choice. ${ }^{90}$ Shared hairbrushes and combs, sometimes less than three of each for over 30 patients $^{91}$ were unlikely to inspire Stoddart's standard that "the hair should be neatly dressed." 92

As well as having some variety, asylum clothes were meant to be durable, washable and suitable for summer and winter. For women, clothes were often old fashioned. Sufficient supplies were needed for them to have a change of dress once a fortnight and clean underwear twice a week, with more underwear allowed for patients of "faulty" or "dirty" habits (incontinence). ${ }^{93}$ In contrast to Carpenter's findings on quality of asylum clothing, the LCC admitted that women's clothes were often "very bad quality", and replacements were low on the agenda, even postwar. ${ }^{94}$ Male patients were allocated two clean shirts a week and a weekly change of undershirt and drawers. ${ }^{95}$ Their clothing could be threadbare or otherwise inadequate, and in some wet and windy locations, overcoats were not distributed, even to men working outdoors. ${ }^{96}$ Men's asylum garb resembled workmen's clothes so they might be indistinguishable from any other workman beyond the asylum walls. ${ }^{97}$ However, there was still a risk of being identified as a patient if attempting to escape, so some men devised ingenious ways to change their clothes: Frederick S probably hid in the grounds for one night, returning the following night to deposit his hospital garb and take workshop clothes belonging to a paid worker. ${ }^{98}$

Asylum clothes were often crumpled, baggy, and fitted poorly. Admission photographs of women patients at Colney Hatch reveal much about their clothes, indicating ways in which they tried to convey their individuality and exert a degree of choice. They also provide clues to their physical health and state of mind. ${ }^{99}$ Regarding clothing, Jenny K's and Rachel K's clothes were identical, apart from some mismatched, probably replaced buttons, and a blouse under Jenny's dress (Fig. 6.3). Jenny's blouse may have been her way of projecting some individuality, despite expected uniformity, while others tucked in their collars to make v-necks, or added detachable lace collars or bows (Fig. 6.4). Importantly, staff respected these individual choices of clothing adjustments. Photographs of most male patients at Colney Hatch show greater uniformity in the design of their clothes, although variation in colour cannot be assessed in the images. Slightly built 15-year-old Harold $\mathrm{H}$ looked nonplussed in his 

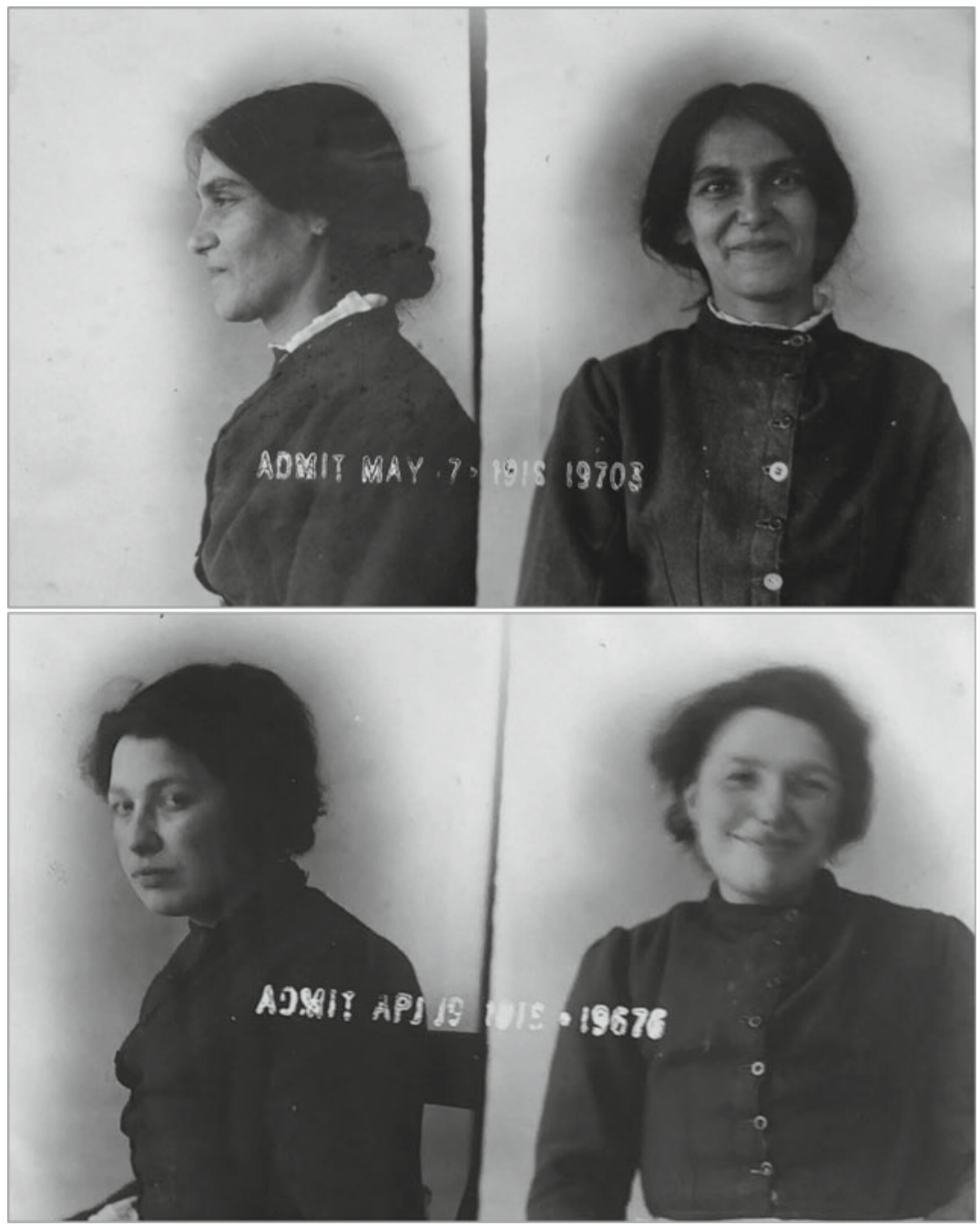

Fig. 6.3 Jenny $\mathrm{K}$ and Rachel $\mathrm{K}$ : uniform asylum clothes (Photographs of female patients at Colney Hatch 1918-1920 H12/CH/B/18/004 LMA) 


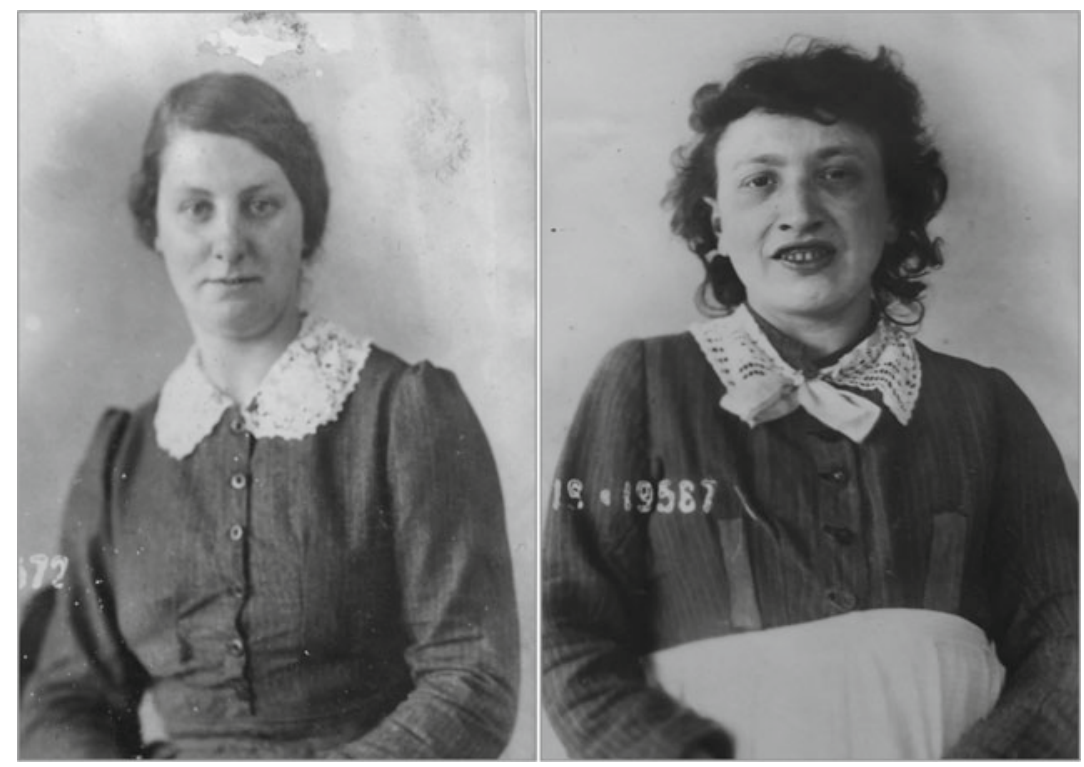

Fig. 6.4 Annie L and Annie S: detachable lace collars (Photographs of female patients at Colney Hatch 1918-1920 H12/CH/B/18/004 LMA)

over-sized asylum-issue of shirt, tie, waistcoat and jacket. Unusually, Max $\mathrm{G}$, was photographed in his shirt sleeves, failing to make eye contact and in a defiant pose (Fig. 6.5). ${ }^{100}$

One patient, Margarita K (Fig. 6.6), had a tear in her sleeve and a steadying hand on her shoulder, and a dress with no buttons on the front, unlike most of the other women's clothes. We do not know how the sleeve was torn, but the hand on Margarita's shoulder suggests a staff member trying to settle her, and the lack of buttons may have been to prevent her from removing her clothes. The pose suggests genuine care of the staff member attending to her.

Other aspects of clothing management could be undignified and detrimental to well-being and recovery, such as staff searching patients' clothes every night, in case they had concealed a home-made weapon in them. ${ }^{101}$ However, a new dimension was added to discussion on dignity and patients' clothing with the arrival of service patients. Initially, the Board 

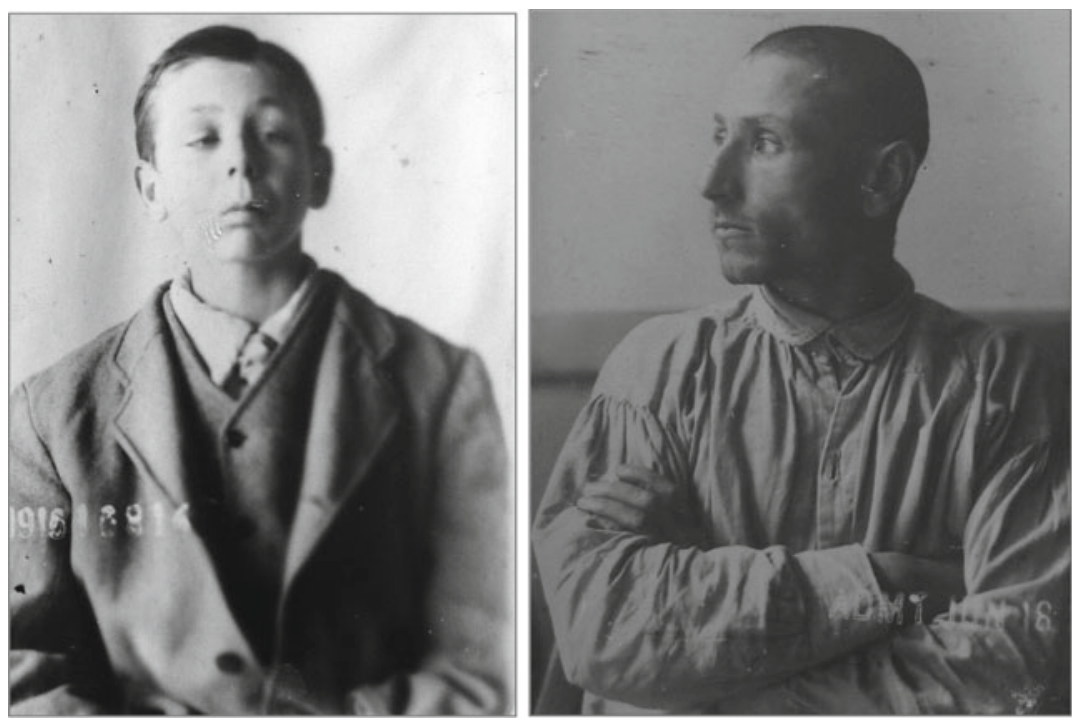

Fig. 6.5 Harold $\mathrm{H}$ and Max G: bewildered and defiant (Photographs of male patients at Colney Hatch 1908-1920 H12/CH/B/19/003 LMA)

agreed with the military authorities that they would have a distinctive uniform, to avoid the stigma of pauper lunatics' asylum clothes and distinguish them as war-traumatised. ${ }^{102}$ The uniform was abandoned when many refused to wear it, as it triggered memories of their army uniforms and their traumatic experiences, and it had a detrimental effect on recovery. ${ }^{103}$ As an alternative, service patients wore tweed suits, "to distinguish them from the others, and to mark the appreciation of a grateful county for their war services". ${ }^{104}$ By providing better and less workman-like clothes for service patients and commenting that their clothing could affect recovery, the authorities tacitly acknowledged the drawbacks of the garments provided to pauper lunatics. 


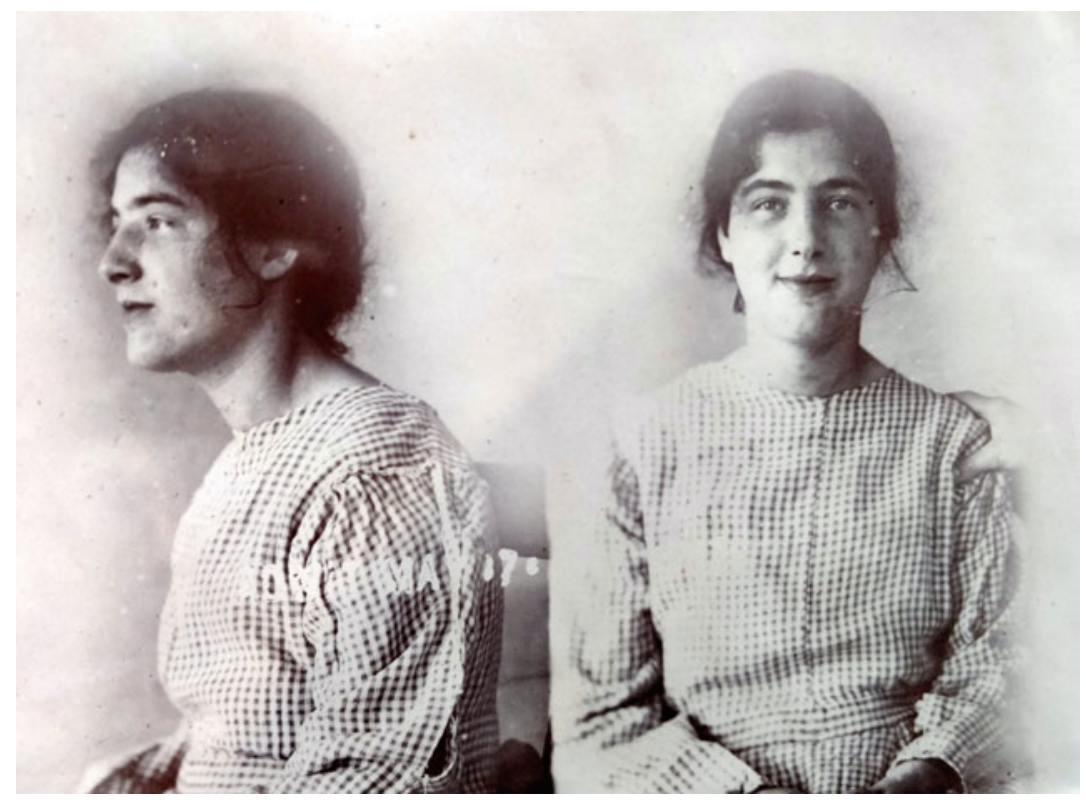

Fig. 6.6 Margarita $\mathrm{K}$, with a steadying hand on her shoulder (Photographs of female patients at Colney Hatch 1918-1920 H12/CH/B/18/004 LMA)

\section{Cleanliness}

From time to time, asylums sought assistance to help rid their buildings of beetles and cockroaches which occasionally appeared in the food. ${ }^{105}$ Some asylums employed rat catchers, ${ }^{106}$ and at Hanwell, rats bred in the asylum tip and escaped along the railway bank if the rat catcher disturbed them. To use rat poison, also a risk to humans, required special permission, and in this instance, it was granted. ${ }^{107}$ In the pre-war decades, discoveries in microbiology increased understanding of disease prevention and the need for hygiene and public health measures. The Board was aware of these developments, but this knowledge was a far cry from the conditions on asylum wards, where practices were often unhygienic and neither met recommended standards nor those described by Carpenter. ${ }^{108}$ Poor hygiene contributed to spread of infection in asylums, such as tuberculosis (discussed further in the next chapter). Some patients with that disease coughed up sputum, spat it on the floor where it dried and mixed 
with dust, creating conditions for it to be inhaled by others. ${ }^{109}$ Wartime overcrowding hindered Mercier's goal that "The wards of a lunatic asylum should be as clean as a man-of-war". 110

As well as inadequate hygiene measures to curb spread of infectious diseases, facilities to ensure personal cleanliness were far from enticing. For example, asylum patients often had to share toothbrushes with other patients. Not only was this unhygienic, but it was incompatible with expectations on the outside: a soldier's kit, for example, included a toothbrush for his personal use. ${ }^{111}$ The Board praised asylums in which each patient had their own toothbrush labelled with their name, highlighting that other asylums did not do the same. ${ }^{112}$ Some patients did not have their own hand towels, even on infirmary wards. One former patient recalled 3 towels for over 30 patients. ${ }^{113}$ At Long Grove, patients had their own towels, but only had cold water for washing. ${ }^{114}$ A nurse who gave evidence at the Cobb Inquiry mentioned that some wards where she worked lacked washbasins and patients washed in a shared trough. Those patients also lacked towels, so dried themselves on their night clothes or on a soiled sheet from the dirty linen cupboard. ${ }^{115}$

In Goffman's analysis, "territories of the self are violated" in institutions, with removal of the boundaries which a person would put between himself and the next person if living in the community: contamination could be physical and psychological. ${ }^{116}$ Alongside shared toothbrushes and towels, undignified asylum bathing routines fit this model. Despite acknowledgement that bathing could be beneficial for more than just ensuring cleanliness, its therapeutic potential was frequently neglected. An asylum chaplain, giving evidence to the Cobb Inquiry, described it as "positive indecency" with patients "treated more like animals" than human beings. ${ }^{117}$ His report was incompatible with Mercier's stipulation that staff should never allow a "crowd of naked patients [to] accumulate". ${ }^{118}$ Mercier also criticised the lack of privacy due to an absence of curtains between baths and "spray baths" (showers), ${ }^{119}$ and Stoddart criticised the rigid weekly bathing regime as punitive and "unnecessary tyranny" and requested flexibility for patients accustomed to bathing daily. ${ }^{120}$

The mechanistic rules for safe bathing which were displayed in the bathrooms had to be followed even though they disregarded the psychological wellbeing of patients. ${ }^{121}$ They included directions on how to fill the bath to avoid scalding (although that still occurred), the need to change the bath water between patients, never to put a patient's head 
under water, and only to give cold baths on medical advice. ${ }^{122}$ The rules also required staff to supervise patients when bathing even though they did not all require it, and to inspect patients' bodies for bruises. ${ }^{123}$ In reality, bruises told the staff little, as examination would not disclose their causes. The weekly mass bathing ritual in accordance with the bathing rules was convenient for staff. Checking for bruises legitimised it as a pseudo-medical routine, but the process undermined dignity, individuality, autonomy and rehabilitation, and the rules probably protected staff more than patients.

Carpenter noted that, pre-war, sanitary facilities in the Hampshire asylums compared favourably to those which Benjamin Seebohm Rowntree found in working-class York around 1900. ${ }^{124}$ However, judging by the Board repeatedly cajoling asylums to improve sanitary facilities, ${ }^{125}$ this was not the asylum picture nationally. In some asylums, water closets (WCs) merely required decorating. ${ }^{126}$ In others, more were needed, ideally one for 12 patients, because "insufficiency leads to constant squabbling and contention among the patients". ${ }^{127}$ Elsewhere, WCs had no doors. ${ }^{128}$ Fearful of being negligent in their duty to observe patients to keep them safe, VCs repeatedly argued for toilets without doors, although the Board recommended "dwarf doors" as a minimum. ${ }^{129}$ Mercier stipulated that the top of closet doors should be at least $5 \mathrm{ft} 6$ inches $(1.7 \mathrm{~m})$ from the floor, to ensure that the occupant was "decently concealed". There could be a gap at floor level up to $1 \mathrm{ft}(30 \mathrm{~cm})$ so it was obvious if it was occupied, ${ }^{130}$ which would also allow staff to monitor patients who "Must not get the opportunity of loitering and spending their time in the closets - a time which is frequently occupied in evil practices."131 Perhaps the greatest fear for staff was to be blamed if a patient took their own life by hanging on exposed pipework. That risk, however, was remediable as pipes could be enclosed. Nevertheless, some VCs ignored the Board's instructions to do that, even after a suicide by hanging in their own asylum. Reasons given included that it "would involve too great a cost". ${ }^{132}$ Even the Board naming-and-shaming to indicate its disapproval of negligent VCs, ${ }^{133}$ did not ensure action, raising questions about the principles upon which those running the asylums made their decisions.

Another upgrade required for lavatories in some asylums was to replace earth closets (ECs) by WCs. Public health experts had recommended this since the turn of the century, particularly in population-dense towns and cities, where, by 1914, ECs were rare. ${ }^{134}$ Asylums, despite their rural locations were mini-population dense areas and required similar facilities. 
Mercier did not mention ECs in his book of asylum management in 1898, appearing unaware of their continued asylum use. ${ }^{135}$ The Board criticised their on-going use pre-war, such as at Prestwich, where patients used ECs while the medical superintendent and senior staff had WCs. Lomax drew attention to the ECs and the "closet-barrow gang" of patients who emptied them. ${ }^{136}$ Prestwich's VC made no changes between the time of publication of Lomax's book and the Cobb Inquiry nine months later, despite the asylum being under scrutiny of the Board and of the Ministry of Health. When the inquiry panel asked the chairman of Prestwich VC what he was doing about the ECs, he answered: "I have made a note of it. We are getting the contract in now." 137 The inquiry indicated the VC's apathy towards improving sanitation, hygiene and personal dignity of patients and eliminating the need for the closet-barrow gang, in stark contrast to it providing modern facilities for those at the top of the asylum hierarchy. The inquiry risked creating adverse publicity for Prestwich concerning their standards of care in a way that Lomax's book (where the asylum was unnamed) had not.

\section{Night Times}

In overcrowded asylums, mattresses were placed on floors and beds made up in washing areas and store-rooms. ${ }^{138}$ Straw paillasses on old fashioned wooden bedsteads without springs, a shortage of sheets and blankets, and sometimes two patients in one bed with a pillow at each end was hardly conducive to a good night's sleep. ${ }^{139}$ Some wards lacked blinds, so light could disrupt patients' sleep in summer time. ${ }^{140}$ Some asylums allocated night-wear to individual patients, a practice which the Board wanted more widely adopted. ${ }^{141}$ Elsewhere, the patients' nightwear was bundled-up in the morning and re-distributed randomly the following night. ${ }^{142}$ Even just numbering garments could have ensured more hygienic and dignified redistribution. ${ }^{143}$ Patients might also be moved from one bed to another, but when sheets were only changed once a week, they could be sleeping in a stranger's bed linen. ${ }^{144}$ Mercier and the Board made other practical suggestions to overcome some sleep-disturbing environmental factors, such as providing individual chamber pots for night use since toilets were often at a distance, and instructing attendants to wear "noiseless slippers", not to flash their lanterns in patients' faces and not to wake sleeping patients to give them medication. ${ }^{145}$ 
Typical asylum bed time for patients was about 8 p.m., when the night shift came on duty, but Board inspectors were "more than pleased" when they saw patients socialising until 10 p.m. ${ }^{146}$ At Horton, before it became a war hospital, the Board wrote: "We might from all appearances have been in the rooms of a working men's club, where the amusements and recreations of an ordinary social evening were in progress." The patients were reading, playing billiards, cards or dominoes, and singing songs round a piano. ${ }^{147}$ Smoking was encouraged as a social pass-time. ${ }^{148}$ Some women also had evening privileges, with gender suitable activities such as needlework. ${ }^{149}$ The Board praised asylums which instigated evening socialising. It encouraged others to follow suit, but by 1922, the practice was still not widespread. ${ }^{150}$ Implementation of Board suggestions was neither promptly nor consistently followed, much to their chagrin at subsequent inspections.

Despite the Board's encouragement for evening socialising, most patients spent over eleven hours in bed each night. Patients considered this regime "monstrous". ${ }^{151}$ The theory that acutely mentally unwell patients needed to rest their brain was extrapolated from the common practice of resting a diseased part of the body to aid recovery, linked to the understanding that mental and physical disorders were caused by similar biological mechanisms. Mercier explained that in acute mental disorders, "the demand upon the energy of the brain is greater than it can supply; it becomes so depleted that it cannot carry on its current function, and the depletion manifests itself in some form of insanity."152 Although Mercier's explanation was for acute mental disorders, the regime frequently extended to the whole asylum. This was irreconcilable with the Board's objective that patients should have as normal a life as possible and with their praise for asylums which allowed patients to stay up late. ${ }^{153}$ Time in bed, like other aspects of asylum culture, was justified by theories, rather than evidence, and dovetailed with asylum organisation and staff convenience. In this instance, it was easier to supervise patients if they were expected to stay in bed, and eleven hours aligned with the seven-times fewer staff on night shift compared to day shift. As with shared bed linen and nightwear, practices convenient for staff and economical for VCs became accepted and therefore unquestioned as part of asylum life even when not in the patients' best interests. 


\section{Patients' Links with People Outside}

Riggall described "those unfortunate folk, who, through no fault of their own, are doomed to live [in an asylum], cut off from their friends and the outside world. No one could possibly explain the monotony of such a life. It has to be experienced to be believed." 154 Having visitors was important, Riggall said, "one can form no idea what these visits mean to people"; and for those without visitors, "I have seen them cry with disappointment on visiting days as they heard the more fortunate ones called out to go down to the visiting-room."155

Visiting hours were restricted, typically a couple of hours on a handful of days each month, unless a patient was dangerously ill, when relatives might be invited to stay day and night. ${ }^{156}$ At Hanwell, patients could have up to 2 visitors at a time, but no infants, and caution was advised about bringing in "children of tender years". Visitors were instructed that conversation with the patient should be comforting and reassuring. They had to obey rules: they must not post patients' letters nor give them money, nor give gratuities to staff who could be dismissed for accepting them. ${ }^{157}$ At Hanwell, visitors were permitted to bring fruit and cake for patients, but that was sometimes prohibited, such as during an outbreak of typhoid when the authorities could not identify a source for it inside the asylum. ${ }^{158}$ Through much of the war, visitors could purchase cake at

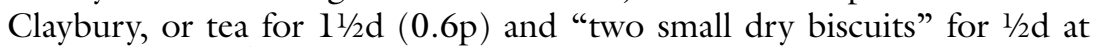
Colney Hatch. ${ }^{159}$ When flour and tea were in short supply, these refreshments indicated recognition of the visitors' often arduous journeys on public transport, and were significant gestures of welcome.

Despite infrequent visiting times, the Board recognised the importance of maintaining contact with family and friends. For patients transferred from their usual asylum to one further away in the process of creating war hospitals, the Board negotiated for the War Office to cover the additional travel costs incurred by visitors, and by patients returning to their home area for trial leave pre-discharge. ${ }^{160}$ The Treasury initially opposed the subsidy, only agreeing after the Board gave them an ultimatum that it would otherwise cease to cooperate to provide accommodation for wounded men. ${ }^{161}$ This was a rare example of timely advocacy by the Board for its asylum patients and their families. The Board also issued instructions to VCs to be lenient when judging if reimbursement should 
be made: assessment should be based on whether visitors were "reasonably able to afford" the additional cost, not on whether they could "scrape together a sufficient amount of money" to do so. ${ }^{162}$ Admirably humanely based, it is less clear how the VCs interpreted the directive or if they informed relatives about the scheme.

Another means of communication with the outside world was by post. The Board criticised wards which failed to provide writing materials, envelopes and stamps. In some asylums, paper was available, but not envelopes, so the patient would write the address on the foot of page and the letter would be taken to the office to be put in an envelope. This was hardly compatible with the Lunacy Act which permitted patients to communicate in confidence with the asylum authorities in charge of their detention, treatment and care. ${ }^{163}$ Sometimes a medical superintendent authorised staff to read all letters so that they knew as much as possible about their patients. ${ }^{164}$ Elsewhere, attendants read them unauthorised. ${ }^{165}$ Staff also opened in-coming letters and parcels, fearing that patients might receive plans for escape or money which might help them do so. It was a pointless intrusion into the patients' privacy in that patients could receive the same from determined visitors. It also contributed to distrust between staff and patients. Practices of staff reading incoming mail seemingly functioned more to protect staff in the event of an escape or other breach in the Lunacy Act rules, by proving that they had done everything in their power to prevent it.

The Journal of Mental Science cited an opinion that letter writing was "highly dangerous" during acute mental disturbance: it could make the patients' condition worse due to

jangling intellects [being] taxed by futile efforts to co-ordinate thought....A patient should not be permitted to tax his diseased brain any more than a patient with pneumonia should be permitted to join in a game of football. This is in reality a question of medicine, and not one of legal ordinance. ${ }^{166}$

This was consistent with other biological hypotheses about resting the disordered brain. ${ }^{167}$ Although it was less overtly compatible with minimising staff effort when compared to the argument about time in bed, it did create one less demand on staff, that of providing patients with writing materials. 


\section{Patients at Work}

In Edwardian times, in the community, working outside the house for men and household duties (or their organisation with tasks delegated to servants) for women, were regarded as civic obligations which could be empowering. 168 The asylums reflected these social norms in the work opportunities given to patients. In addition, it was recognised that suitable asylum work could help self-esteem, distract patients from introspective brooding and provide a barometer of a patient's mental state and recovery. ${ }^{169}$ The laundry, for example, was "the stepping stone to liberty for more patients than any other workshop", according to Lomax, because only the most trustworthy could be placed there. ${ }^{170}$

Mercier regarded work for patients as therapeutic, whether or not useful to the asylum economy. ${ }^{171}$ Likewise, Lomax acknowledged that work had intrinsic therapeutic benefits, although it also subsidised the asylum and could be exploitative, such as the most menial and dirty tasks often falling to patients, whether the closet barrow gang, or others carrying sacks of coal to the wards or distributing patients' chamber pots each evening. ${ }^{172}$ The Board recognised the dual aspects of work, dividing it into categories "daily" and "useful", or work which was solely therapeutic and that which also subsidised the economy. In 1914, the Board praised asylums with work rates of around 90 per cent in daily employment or 75 per cent usefully employed. ${ }^{173}$ Some work necessitated close interaction with staff, such as in the asylum fire brigade, which rapidly became depleted during the war, necessitating training patients and female staff. ${ }^{174}$ Batch-living on overcrowded and understaffed wards contrasted with work-place supervision which provided staff attention to individuals or small groups which could be therapeutic even after decades in the asylum. ${ }^{175}$ However, as Andrew Scull commented, and Kathleen Jones concurred, the purpose of employment in asylums shifted, away from the primary goal of benefit to the patients, to enabling the institution to run more smoothly and cheaply. ${ }^{176}$

For many working class patients, their asylum work mirrored their preadmission daily activities. ${ }^{177}$ However, this was less likely for patients from a growing middle-class population such as governesses, teachers, shop keepers, nurses and office workers. ${ }^{178}$ Within the asylums, male patients had greater occupational diversity than female, although both helped on the wards. Male patients might work with the asylum's craftsmen and tradesmen, but employment for women was usually restricted to domestic 
tasks, mainly in the needlework room, laundry and kitchen. When male staff began to enlist, patients and existing staff took on new roles, and whole teams might change, in line with the principles of asylum gender segregation. ${ }^{179}$ Women took over heavier work previously undertaken by men, ${ }^{180}$ and when female staff began to work on the farms, they supervised female patients working alongside them. ${ }^{181}$ Women patients, as women outside the asylums, took on new roles.

During the war, patients also contributed to the war effort, although sometimes, external policies, politics and opinions impinged on asylum activities, not necessarily in the patients' best interests. For example, the LCC decided that patients would not make garments for soldiers, even if they had the skills, as that risked putting women in the community out of work. ${ }^{182}$ Asylums did, however, purchase wool which allowed patients to knit socks for men in the forces, and some patients helped on war hospital farms, as at Napsbury. ${ }^{183}$ Patients at Colney Hatch collected about 30,000 horse chestnut "conkers" (about $240 \mathrm{~kg}$ ) from the asylum grounds for the Ministry of Munitions to produce cordite, the smokeless powder used as a propellant in ammunition. ${ }^{184}$ Late in the war, asylums collected fruit stones and hard nut shells which were burnt to produce charcoal for gas-mask filters, more effective than standard wood-charcoal. ${ }^{185}$

In addition to these contributions, some asylums undertook paid war work. Claybury took on munitions work, "roughing out" shells, as they had the correct size machinery or furnaces in the boiler room. ${ }^{186}$ A photograph of the boiler room from the medical superintendent's personal collection was labelled "Claybury - making shells, 1915" (Fig. 6.7). Claybury produced 4000 shell bodies which generated $£ 450$ for the asylum. ${ }^{187}$ At another asylum, trustworthy male patients worked with local farmers, who escorted them to the farm and back each day, and who paid a "small charge" to the asylum. A report about the scheme did not mention whether the patients received a share of the fee paid, although we hear that they, and the farmers, found the experience gratifying and neither party abused the system. The Board encouraged other asylums to do the same, but Board archives do not indicate whether that happened. ${ }^{188}$

As with making shells or keeping the boiler furnaces alight, asylum work on an industrial scale could be hazardous. Asylum premises were subject to the Factory and Workshops Act 1907 which aimed to promote health and safety. ${ }^{189}$ Nevertheless, accidents happened. One patient 


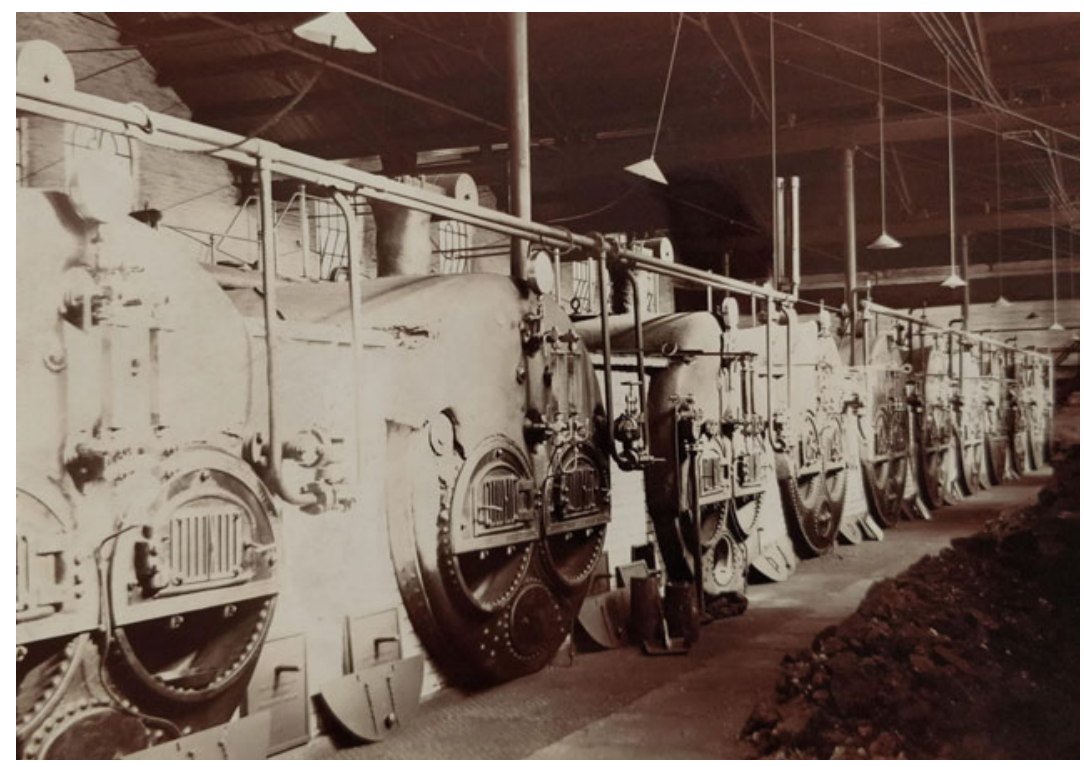

Fig. 6.7 "Claybury - making shells, 1915" (Armstrong-Jones collection, Royal College of Psychiatrists' Archives)

sustained a fracture when his arm caught in the hair-picking machine, 190 the device used to separate out different sorts of horsehair for stuffing mattresses. Laundry work was also dangerous: inadequate training before using the machinery, unhygienic processing of soiled linen, and lack of opportunity or encouragement for hand washing after handling it, all contributed. ${ }^{191}$ Following Henrietta S's death in the laundry at Wakefield Asylum by scalding, the Board criticised the "persistent disregard" of laundry safety regulations. ${ }^{192}$

The VCs were concerned less about patients being injured at work and more that they might escape, the latter indicating that the asylum had failed in its duty under the Lunacy Act. Louis $\mathrm{Z}$ escaped from a party of four patients working with a farm labourer in the cow sheds, and Eugene $\mathrm{T}$, working in the grounds at Colney Hatch, asked the attendant if he could go to the WC then scaled the boundary wall. Eugene was probably not "recaptured", judging by the dates when the VC discussed his escape and his discharge a week later. ${ }^{193}$ In neither case were staff blamed, but 
as a precaution, attendants were issued with whistles should they needed to summon help outdoors. ${ }^{194}$

Mercier justified patients receiving inducements to work, partly to overcome reluctance to work in a system which they did not like and did not want to support. He, like Lomax, disapproved of the widespread practice of giving rewards in kind which were demeaning rather than having the desired objective of promoting self-esteem. ${ }^{195}$ Rewards in kind at Hanwell in 1918 were given to patients who washed the dishes on their ward for a week without any breakages: men received $1 / 2 \mathrm{oz}(14 \mathrm{~g})$ tobacco, and women, 1 oz tea or $1 / 2$ oz sugar. ${ }^{196}$ Since sugar was rationed, using it in this way suggests that it was removed from the pooled supplies and that others did not receive their full allocation.

Patients disliked being paid in kind, and preferred to receive money. ${ }^{197}$ Regarding rewards for working patients, Lomax was among those who advocated for useful payment which patients could use to choose and purchase items in an asylum shop, helping to "increase self-respect and sense of personal value, which the present soulless and machine-made system of asylum administration seems specially designed to destroy."198 Around this time, the idea of using tallies or tokens, rather than real money, was gaining ground. As well as spending tokens, they could be used as fines for wilful misdemeanours or saved and converted to real money at the time of discharge. ${ }^{199}$ Half-a-crown $\left(2 \mathrm{~s} 6 \mathrm{~d}, 12 \frac{1}{1} 2 \mathrm{~d}\right)$ was a convenient reward or incentive for many people to undertake an activity. Patient Joseph $\mathrm{P}$, who stayed up all night to assist with "re-adjusting the clocks in the Institution for "summer time" " received half-a-crown. ${ }^{200} \mathrm{It}$ compared with the daily remuneration of a washer woman in Kensington, west London. ${ }^{201}$ It was also the flat-rate reward which asylums gave to a member of the public who "recaptured" and returned an "escaped lunatic". ${ }^{202}$ In the context of the asylum, probationer nurses were among the lowest paid, and in 1916, after deductions for living-in, they received 8 s a week. ${ }^{203}$ Patients did not work the long and anti-social hours of nurses, so although half-a-crown was low, it was a meaningful amount.

In contrast to the civilian patients, service patients automatically received half-a-crown a week pocket money, whether or not they contributed to the asylum economy. Jealousy and theft by patients without the allowance was reported, and some service patients used the money to gamble, which caused arguments. ${ }^{204}$ Asylums were unsure how to deal with these problems: communal living without safe personal storage space was unconducive to a monetary or a token economy. 
The Board gave no guidance. ${ }^{205}$ Lomax challenged the conclusions of the authorities that patients were inevitably untrustworthy with money. In his view, the more you trust the patients, the better they respond, but "Asylum authorities, of course, are far from believing this; the principle they act upon is just the opposite."206

\section{Conclusions}

According to Kathleen Jones, the asylum regime suited some people. ${ }^{207}$ For others, the standard of care was sufficient for them to live many years beyond the average life expectancy for their generation. ${ }^{208}$ In the asylums, compassion existed, and patients could experience a sense of community. There are indicators that individual staff showed kindness to their patients despite the pressures under which they worked. Asylums also attended to aspects of the diverse religious, linguistic and cultural needs of their patients. Sometimes, following the death or discharge of a patient, relatives donated money or presented a gift to the asylum in gratitude for their care. ${ }^{209}$

Among those in authority, there was limited acknowledgement of the harm which institutions could cause to patients. However, critics mainly from outside the ranks of the public asylums, indicated dismay at practices which were undignified and disrespectful of patients and undermined their self-esteem. Their words often passed unheeded. The Board advocated for patients to have as near normal a life as possible and there were ample guidelines about what a modern asylum should provide. However, these were interpreted and achieved variably, balanced against other needs, particularly cost of provision, constraints of the Lunacy Act, and convenience for staff and leadership, all of which shaped the patients' daily life. Staff convenience also affected the application of practices derived from unproven theories about mechanisms of mental disorder which could hinder the wellbeing of patients.

The Lunacy Act set a financial cap and promoted rigid risk-avoidance. Innovation risked overstepping both of these: it was safer to maintain the status quo than to deviate from it. Thus, the Act encouraged a conservative and laissez faire culture and lethargy towards changing practices. The culture, as demonstrated at Prestwich regarding modernising the ECs was ongoing, rather than just specific to the war years. Some things could not be changed, such as the architecture and external societal pressures, but for many aspects of care, knowing what needed to be done but making 
little effort to do it, was negligence of a particularly distressing kind. Visiting committee minutes repeatedly convey an attitude that anythingwould-do for the lunatics. Some staff and patients spoke up about the deficits, but usually after they had left the asylum. ${ }^{210}$ Relatives and friends of patients rarely appeared to complain. Some had no concerns, but others feared repercussions against the patient if they made a fuss. ${ }^{211}$ Lack of evidence about their concerns might also be due to the authorities destroying correspondence when satisfied that the problem had been dealt with. ${ }^{212}$

In contrast to improving the pauper lunatics' lives, for whom ideas were tardily implemented, or not at all, providing more dignified care, pocket money and better clothing for service patients reflected public concern and received speedy attention. Finding the will and the way was associated with outside interest and the leadership's concerns about adverse publicity. This was evident at Prestwich where the VC began to deal with the ECs only after the Cobb Inquiry. With regard to benefits from public exposure, it is unfortunate that the Board's annual reports were truncated during the war and during the period of post-war reconstruction.

With the Board's tools being persuasion and suggestion, its effectiveness was dubious for motivating unenthusiastic VCs to implement change. The methods were likely to be more successful with asylums whose VCs and medical superintendents were already motivated. Decisions on care were influenced by wider social demands which were not necessarily in the patients' best interests. In austerity, public authorities had to decide who to support, and pauper lunatics were low on the list, hardly helped by their stigmatising designation and by public fear of the disorders from which they suffered and of the asylums where they were confined. Practices introduced for service patients had the potential to underpin improvements for all patients, but they could also inhibit change by creating practical challenges which appeared insurmountable, such as the need to provide safe personal storage space to prevent theft of cash allowances. The war gave everyone additional worries and distractions, making it easy for the public and the authorities to neglect standards of care for pauper lunatics in a culture where minimal provision was accepted as the norm. 


\section{Notes}

1. Steven Cherry, Mental Healthcare in Modern England: The Norfolk Asylum/St. Andrews Hospital 1810-1998 (Woodbridge, Suffolk: Boydell Press, 2003), 144.

2. D Thomson, "A Descriptive Record of the Conversion of a County Asylum into a War Hospital for Sick and Wounded Soldiers in 1915," Journal of Mental Science (JMS) 62 (1916): 109-35, 122-23, 114.

3. E Marriott Cooke and C Hubert Bond, History of the Asylum War Hospitals (London: HMSO, 1920), 7.

4. First Annual Report of the Board of Control, for the Year 1914 (London: HMSO, 1916) (BoC AR 1914), Part 2, Oxford Asylum 4 August 1914, 295.

5. BoC AR 1914, Part 2, Cambridge and Isle of Ely Asylum 21 October 1914, 202.

6. BoC AR 1914, Part 2, Carmarthen Asylum 7 May 1914, 205.

7. Russell Barton, Institutional Neurosis (Bristol: John Wright and Sons, 1959), 11.

8. Erving Goffman, Asylums: Essays on the Social Situation of Mental Patients and Other Inmates (1961; Harmondsworth: Penguin, 1980), 23-24.

9. Roger Lee and Lewis Jones, The Fundamentals of Good Medical Care (Chicago: Chicago University Press, 1933).

10. Charles Mercier, Lunatic Asylums, Their Organisation and Management (London: Griffin, 1894); Charles Mercier, The Attendant's Companion: A Manual of the Duties of Attendants in Lunatic Asylums (London: J and A Churchill, 1898).

11. BoC AR 1914, Part 2, Oxford Asylum 4 August 1914, 296.

12. Mary Riggall, Reminiscences of a Stay in a Mental Hospital (London: AH Stockwell, 1929); Rachel Grant-Smith, The Experiences of an Asylum Patient (London: Allen and Unwin, 1922); James Scott, Sane in Asylum Walls (London: Fowler Wright, 1931); D Davidson, Remembrances of a Religio-Maniac (Stratford-on-Avon: Shakespeare, 1912); Clifford Beers, A Mind That Found Itself (London: Longmans Green, 1908).

13. Riggall, Reminiscences, 23.

14. Ministry of Health (MoH), Report on of the Committee on Administration of Public Mental Hospitals Cmd. 1730 (Chairman: Sir Cyril Cobb) (London: HMSO, 1922); Montagu Lomax, The Experiences of an Asylum Doctor (London: Allen and Unwin, 1921).

15. Lunacy Act 1890 section 188.

16. Committee on the Administration of Public Mental Hospitals (Chairman: Sir Cyril Cobb) (Cobb Inquiry), 30 March 1922 Edward Mason Q:2113, MH 58/220 TNA. 
17. BoC AR 1914, Part 2: Durham Asylum 8 May 1914, 222; City of London Asylum 8 June 1914, 362; Dorset Asylum 12 May 1914, 220; Rainhill Asylum 21 February 1914, 250.

18. Mercier, Attendant's Companion, 2.

19. BoC AR 1914, Part 2, Kesteven Asylum 27 January 1914, 262; Bristol Asylum 9 May 1914, 347.

20. Grant-Smith, Experiences, 50.

21. Grant-Smith, Experiences, 82.

22. Claire Hilton, Improving Psychiatric Care for Older People: Barbara Robb's Campaign 1965-1975 (London: Palgrave Macmillan, 2017), 119.

23. Grant-Smith, Experiences, 82.

24. BoC AR 1914, Part 2, Whittingham Asylum 28 February 1914, 253; Kesteven Asylum 27 January 1914, 262; Bristol Asylum 9 May 1914, 347.

25. $\mathrm{MoH}$, Committee on Administration, 6.

26. Kathleen Jones, Mental Health and Social Policy, 1845-1959 (London: Routledge and Kegan Paul, 1967), 107.

27. England Census, https://www.ancestry.co.uk/cs/us/uk-census-records. Patient at Coulsdon Asylum 1891 and Horton Asylum 1911; Claybury: Female patient case notes 1907, Redbridge Heritage Centre.

28. Goffman, Asylums, 270.

29. Diane Carpenter, “Above All a Patient Should Never Be Terrified': An Examination of Mental Health Care and Treatment in Hampshire 1845-1914" ( $\mathrm{PhD}$ thesis, University of Portsmouth, 2010), https://researchportal.port.ac.uk/portal/files/5877161/Diane_ Carpenter_PhD_Thesis_2010.pdf, 25, 120.

30. Carpenter, "Above All": 166.

31. Riggall, Reminiscences, Preface, 17.

32. BoC AR 1914, Part 2, Brecon and Radnor Asylum 6 May 1914, 199; Kesteven Asylum 27 January 1914, 262.

33. Bernard Hollander, The First Signs of Insanity: Their Prevention and Treatment (London: Stanley Paul and Co, 1912), 19-20.

34. Mercier, Attendant's Companion, 1.

35. Mercier, Organisation, 120.

36. BoC AR 1914, Part 2, Glamorgan Asylum 4 November 1914, 228; Severalls Asylum 27 October 1914, 226.

37. BoC AR 1914, Part 2, Durham Asylum 8 May 1914, 222.

38. BoC AR 1914, Part 2, Cornwall Asylum 25 May 1914, 209-10; Rainhill Asylum 21 February 1914, 250; Mercier, Attendant's Companion, 72.

39. BoC AR 1914, Part 2, Berks Asylum 6 May 1914, 197; Derby Borough Asylum 31 January 1914, 352; Portsmouth Asylum 2 April 1914, 372.

40. BoC AR 1914, Part 2, Suffolk Asylum 5 June 1914, 308; Hereford Asylum 4 May 1914, 235. 
41. Claybury LCC/MIN/00947 Meeting, 20 July 1916, 170 LMA.

42. LCC LCC/MIN/00580 Meeting, 27 July 1915, 698; LCC LCC/MIN/00583 Meetings: 29 January 1918, 281; 30 April 1918, 500 LMA.

43. Mercier, Attendant's Companion, 72.

44. Diana Cordea, "Two Approaches on the Philosophy of Separate Spheres in Mid Victorian England: John Ruskin and John Stuart Mill,” Procedia-Social and Behavioral Sciences 71 (2013): 115-22, 115.

45. Vera Brittain, Testament of Youth (1933; London: Virago Press, 1982), 114.

46. Lunacy Act 1890, section 53.

47. Riggall, Reminiscences, 6.

48. BoC AR 1914, Part 2, Bexley Asylum 20 March 1914, 266.

49. BoC AR 1914, Part 2, Dorset Asylum 12 May 1914, 220.

50. BoC W/FM, 9 December 1914, 271 MH 50/43 TNA.

51. BoC AR 1914, Part 1, 57-58.

52. BoC AR 1914, Part 2, Cardiff Asylum 2 November 1914, 349; Cobb Inquiry, "Reports of Visits to Mental Institutions: Hanwell" 1922, MH 58/221 TNA.

53. Mercier, Organisation, 57; BoC AR 1914, Part 2, West Ham Asylum 6 February 1914, 377.

54. Claybury LCC/MIN/00949 Meeting, 18 July 1918, 120 LMA.

55. Mercier, Organisation, 88, 100.

56. Hanwell Hll/HLL/A/06/05 draft annual report 1916 LMA.

57. Claybury LCC/MIN/00945 Meetings: 17 September 1914,$161 ; 15$ October 1914, 198 LMA; Colney Hatch LCC/MIN/01003 Meeting, 6 November 1914, 154 LMA; Claybury LCC/MIN/00946 Meeting, 28 October 1914, 262 LMA.

58. Hanwell LCC/MIN/01096 Meeting, 20 November 1916, 241 LMA; Diana Gittins, Madness in Its Place: Narratives of Severalls Hospital, 1913-1997 (London: Routledge, 1998), 170.

59. Hanwell LCC/MIN/01095 Meeting, 26 April 1915, 17-18 LMA.

60. Claybury LCC/MIN/00945 Meeting, 30 April 1914, 64 LMA; Claybury LCC/MIN/00946 Meeting, 13 May 1915, 125 LMA; LCC LCC/MIN/00581 Meeting, 6 June 1916, 637 LMA.

61. Colney Hatch $\mathrm{H1} 2 / \mathrm{CH} / \mathrm{D} / 02 / 005$ Special grants for entertainments and sporting events for patients and staff 1918-1939 LMA.

62. Lunacy Act 1890 section 276 (1) (a).

63. Riggall, Reminiscences, 14.

64. Riggall, Reminiscences, 21-22.

65. Lunacy Act 1890 section 277 (3); BoC AR 1914, Part 2, North Wales Asylum 20 March 1914, 214. 
66. Colney Hatch LCC/MIN/01001 Meeting, 10 October 1913, 255-56 LMA.

67. Colney Hatch LCC/MIN/01005 Meeting, 28 July 1916, 230 LMA.

68. Colney Hatch LCC/MIN/01001 Meeting, 10 October 1913, 255-56 LMA.

69. Colney Hatch LCC/MIN/01002 Meeting, 24 April 1914, 215 LMA.

70. Colney Hatch LCC/MIN/01005 Meetings: 30 June 1916, 203; 20 October 1916, 292-94; LCC/MIN/01007 Meetings: 11 January 1918, 88; 17 May 1918, 16 LMA.

71. Colney Hatch LCC/MIN/01005 Meeting, 20 October 1916, 292-94 LMA.

72. Colney Hatch LCC/MIN/01007 Meeting, 24 January 1919, 227 LMA.

73. LCC LCC/MIN/00584 Meeting, 29 October 1918, 30 LMA; Colney Hatch LCC/MIN/01007 Meeting, 19 April 1918, 64 LMA; Colney Hatch LCC/MIN/01005 Meeting, 7 April 1916, 120 LMA.

74. LCC LCC/MIN/00581 Meeting, 29 February 1916, 393 LMA.

75. Colney Hatch LCC/MIN/01005 Meeting, 14 January 1916, 26 LMA.

76. H Cuff, "The Belgian Refugees at Alexandra Palace," Hospital 26 (September 1914): 699-700.

77. Colney Hatch LCC/MIN/01005 Meeting, 14 January 1916, 252-56 LMA; BoC, circular to MSs, War Refugees, 3 January 1916, $440 \mathrm{MH}$ 51/240 TNA.

78. LCC LCC/MIN/00580 Meeting, 24 November 1914, 9; LCC LCC/MIN/00584 Meeting, 25 February 1919, 301 LMA.

79. Colney Hatch LCC/MIN/01004 Meeting, 12 March 1915, 4 LMA.

80. Colney Hatch LCC/MIN/01005 Meeting, 19 May 1916, 157 LMA; Fourth Annual Report of the Board of Control, for the Year 1917 (London: HMSO, 1918) (BoC AR 1917); Fifth Anmual Report of the Board of Control, for the Year 1918 (London: HMSO, 1919).

81. Goffman, Asylums, 28-30.

82. Rebecca Wynter, “'Good in All Respects': Appearance and Dress at Staffordshire County Lunatic Asylum, 1818-54," History of Psychiatry 22 (2011): 40-57.

83. Lomax, Experiences, 57-58.

84. Carpenter, "Above All": 154; BoC AR 1914, Part 2, Lancaster Asylum 22 July 1914, 247; Mercier, Organisation, 78.

85. Lomax, Experiences, 57-58.

86. Jane Hamlett and Lesley Hoskins, "Comfort in Small Things? Clothing, Control and Agency in County Lunatic Asylums in Nineteenth- and Early Twentieth-Century England," Journal of Victorian Culture 18 (2013): 93-114.

87. Hamlett and Hoskins, "Comfort in Small Things?": 98. 
88. BoC AR 1914, Part 2, Prestwich Asylum 4 March 1914, 247.

89. BoC AR 1914, Part 2, Lancaster Asylum 22 July 1914, 247.

90. Mercier, Attendant's Companion, 65; BoC AR 1914, Part 2, Hull City Asylum 12 October 1914, 357.

91. $B o C A R$ 1914, Part 2, Yorkshire (East Riding) Asylum 13 October 1914, 326; Cobb Inquiry, 15 March 1922 Mr. Sale Q:664, 723-24, MH 58/219 TNA.

92. William Stoddart, Mental Nursing (London: Scientific Press, 1916), 87.

93. Mercier, Organisation, 81.

94. Carpenter, "Above All": 166; LCC LCC/MIN/00754 Miscellaneous sub-committees, meeting, 19 November 1919, 148 LMA.

95. Mercier, Organisation, 82.

96. BoC, Memorandum for the Minister of Health on Mr. Montagu Lomax's book The Experiences of an Asylum Doctor, 21 September 1921 MH 58/222 TNA.

97. Lomax, Experiences, 59.

98. Colney Hatch LCC/MIN/01004 Meeting, 12 March 1915, 7 LMA.

99. Colney Hatch $\mathrm{H} 12 / \mathrm{CH} / \mathrm{B} / 18 / 004$ Photographs of female patients admitted and discharged 1918-1920 LMA.

100. Colney Hatch $\mathrm{H} 12 / \mathrm{CH} / \mathrm{B} / 19 / 003$ Photographs of male patients admitted and discharged 1908-1920 LMA.

101. Mercier, Attendant's Companion, 24; Hamlett and Hoskins, "Comfort in Small Things?": 105.

102. LCC LCC/MIN/00582 Meeting, 21 March 1917, 498 LMA.

103. BoC, letter to War Pensions etc. Statutory Committee, 4 June 1917 MH 51/692; Hanwell, H11/HLL/A/14/003/012/001 Letter book, including in-letters and copies of out-letters, statistics and other information, 1 April 1919, 110 LMA.

104. Lomax, Experiences, 57.

105. Hanwell LCC/MIN/01093 Meeting, 27 April 1914, 197 LMA.

106. LCC LCC/MIN/00584 Meeting, 17 December 1918, 158 LMA.

107. Hanwell LCC/MIN/01094, 9 November 1914, 131-32 LMA.

108. Carpenter, “Above All”: 166; Stoddart, Mental Nursing, 87.

109. Hanwell LCC/MIN/01098, 8 April 1918, 6-7 LMA.

110. Mercier, Attendant's Companion, 69.

111. Anon. "Oxen Thigh Bones to Make Wartime Brushes," British Dental Journal 217 (2014): 61.

112. BoC AR 1914, Part 2, Cardiff Asylum 2 November 1914, 349; Whittingham Asylum 28 February 1914, 254. Cobb Inquiry, 11 April 1922 Miss Bartlett (Birmingham VC) Q:3197-98, MH 58/220 TNA.

113. Cobb Inquiry, 15 March 1922 Mr. Sale Q:664, 723-24, MH 58/219 TNA. 
114. Cobb Inquiry, 30 March 1922 Dr. Ogilvy Q:1900, 1907, MH 58/220 TNA.

115. Cobb Inquiry, 16 March 1922 Nurse Jane Dagg Q:1003-23, MH $58 / 219$ TNA.

116. Goffman, Asylums, 31-34.

117. Cobb Inquiry, 6 April 1922 Rev JJ Brownhill Q:2422-26, MH 58/220 TNA.

118. Mercier, Attendant's Companion, 63.

119. BoC AR 1914, Part 2, Claybury Asylum 27 June 1914, 269; Storthes Hall Asylum 19 May 1914, 334.

120. Stoddart, Mental Nursing, 77.

121. BoC AR 1914, Part 2, Kesteven Asylum 27 January 1914, 262.

122. Mercier, Attendant's Companion, 42; BoC AR 1917, 38-39; BoC, Bathing Rules (to be displayed) MH 51/239 TNA.

123. BoC AR 1914, Part 2, Kesteven Asylum 27 January 1914, 262-63.

124. Carpenter, "Above All": 51.

125. E.g. BoC AR 1914, Part 2, Bucks Asylum 30 October 1914, 200.

126. BoC AR 1914, Part 2, Brentwood Asylum 30 June 1914, 224.

127. Mercier, Organisation, 37.

128. Colney Hatch LCC/MIN/01007 Meeting, 12 July 1918 Between pp. 111-12, LMA.

129. BoC AR 1914, Part 2, Menston Asylum 14 May 1914, 330.

130. Mercier, Organisation, 37.

131. Mercier, Attendant's Companion, 64.

132. BoC AR 1914, Part 1, 27.

133. BoC AR 1914, Part 2, Salop Asylum 8 July 1914, 297.

134. Arthur Newsholme, Hygiene: A Manual of Personal and Public Health (London: George Gill and Sons Ltd, 1902); "The City of Coventry: Local Government and Public Services," 275-98, in A History of the County of Warwick: Volume 8, the City of Coventry and Borough of Warwick, ed. WB Stephens (London: Victoria County History, 1969).

135. Mercier, Organisation, 37.

136. Lomax, Experiences, 106-7; BoC, Memorandum for the Minister of Health on Mr. Montagu Lomax's book The Experiences of an Asylum Doctor, 21 September $1921 \mathrm{MH} 58 / 222$ TNA.

137. Cobb Inquiry, 23 March 1922 JR Smith (chairman, Prestwich VC) Q:1311, MH 58/219 TNA.

138. BoC AR 1914, Part 2, Wotton and Barnwood Asylums 17 October 1914, 231; Glamorgan Asylum 4 November 1914, 229.

139. LCC LCC/MIN/00583 Meeting, 30 April 1918, 522. Cobb Inquiry, 16 March 1922 Nurse Jane Dagg Q:983-44 and 991-93, MH 58/219 TNA.

140. BoC AR 1914, Part 2, Whittingham Asylum 28 February 1914, 254. 
141. BoC AR 1914, Part 2, West Sussex Asylum 3 April 1914, 315-16.

142. Cobb Inquiry, 15 March 1922 Mr. Sale Q:728, MH 58/219 TNA.

143. Cobb Inquiry, 30 March 1922 Dr. Ogilvy Q:1898, MH 58/220 TNA.

144. Cobb Inquiry, 6 April 1922 WH Skevington Q:2607-8, MH 58/220 TNA.

145. BoC AR 1914, Part 2, Norwich City Asylum 10 June 1914, 368; Mercier, Attendant's Companion, 81, 90-91.

146. BoC AR 1914, Part 2, Long Grove Asylum 11 December 1914, 277; Horton Asylum 4 December 1914, 275.

147. BoC AR 1914, Part 2, Horton Asylum 4 December 1914, 275.

148. BoC AR 1914, Part 2, Prestwich Asylum 4 March 1914, 247.

149. BoC AR 1914, Part 2, Long Grove Asylum 11 December 1914, 278.

150. Cobb Inquiry, 30 March 1922 Dr. Ogilvy Q:1888-89, MH 58/220 TNA.

151. Cobb Inquiry, 15 March 1922 AM Donaldson Q:662, MH 58/219 TNA.

152. Charles Mercier, A Textbook of Insanity (London: George Allen and Unwin, 1914), 14.

153. BoC AR 1914, Part 2, Horton Asylum 4 December 1914, 275; Long Grove Asylum 11 December 1914, 277.

154. Riggall, Reminiscences, 23.

155. Riggall, Reminiscences, 9.

156. Berkshire Mental Hospital, "Interim Report of the House SubCommittee on the Report of the Departmental Committee of Inquiry dated 1922 and the Recommendations of the Board of Control Resulting from the Inquiry. Berkshire Mental Hospital, 25 May 1923,” MH 51/686 TNA; Claybury LCC/MIN/00945 Meeting, 20 August 2014, 178 LMA.

157. Hanwell H11/HLL/A/14/003/012/001 Letter book, including inletters and copies of out-letters, statistics and other information 19151927, 86 LMA.

158. Hanwell LCC/MIN/01095 Meeting, 19 July 1915, 126 LMA.

159. Claybury LCC/MIN/00948 Meeting: 21 June 1917, 123; 11 October 1917, 219 LMA; Colney Hatch LCC/MIN/01006 Meeting, 4 May 1917, 170 LMA.

160. Napsbury H50/A/01/024 Meeting, 29 August 1915, 138-39 LMA.

161. BoC W/FM, 14 July 1915, $481 \mathrm{MH} \mathrm{50/43} \mathrm{TNA.}$

162. Napsbury H50/A/01/025 Meeting, 18 December 1915, 9-10; BoC letter to VC, 16 December 1915 LMA.

163. Lunacy Act 1890 section 41; BoC AR 1914, Part 2, Prestwich Asylum 4 March 1914, 245.

164. Cobb Inquiry, 30 March 1922 Dr. Ogilvy Q:1915, MH 58/220 TNA.

165. Lomax, Experiences, 71. 
166. Anon. “Asylum Report,” JMS 61 (1915): 288-321, 294.

167. Mercier, Textbook of Insanity, 14.

168. Sarah Chaney, "Useful Members of Society or Motiveless Malingerers? Occupation and Malingering in British Asylum Psychiatry, 1870-1914," 276-297, in Work, Psychiatry and Society c. 1750-2015, ed. Waltraud Ernst (Manchester: Manchester University Press, 2016), 291.

169. Chaney, "Useful Members": 280; Claybury, Female patient case notes 1917, Louise F, Redbridge Heritage Centre.

170. Lomax, Experiences, 105.

171. Mercier, Attendant's Companion, 71.

172. LCC LCC/MIN/00579 Meeting, 25 November 1913, 38 LMA; Claybury LCC/MIN/00948 Meeting, 13 September 1917, 193-94 LMA; Lomax, Experiences, 112-14.

173. BoC AR 1914, Part 2, Brecon and Radnor Asylum 6 May 1914, 199; Parkside Asylum 2 July 1914, 208.

174. Hanwell LCC/MIN/01095 Meeting, 7 June 1915, 66-67 LMA; Colney Hatch LCC/MIN/01004 Meeting, 18 June 1915, 124 LMA.

175. Mercier, Organisation, 2.

176. Andrew Scull, The Most Solitary of Afflictions: Madness and Society in Britain, 1700-1900 (New Haven and London: Yale University Press, 1993), 289; Kathleen Jones, "The Culture of the Mental Hospital," 17-27, in 150 Years of British Psychiatry 1841-1991, ed. German Berrios and Hugh Freeman (London: Gaskell, 1991), 21.

177. Carpenter, "Above All": 156, 158; BoC AR 1914, Part 2, The Chestnuts, Walthamstow, 28 October 1914, 228.

178. Chaney, "Useful Members": 278.

179. LCC LCC/MIN/00581 Meeting, 30 November 1915, 125 LMA.

180. Hanwell LCC/MIN/01096 Meeting, 23 October 1916, 214 LMA.

181. Claybury LCC/MIN/00948 Meeting, I March 1917, 41 LMA.

182. LCC LCC/MIN/00579 Meeting, 29 September 1914, 647 LMA.

183. Colney Hatch $\mathrm{H} 12 / \mathrm{CH} / \mathrm{A} / 08 / 001$ Reports to Sub-Committee 22 February 1918, 20; 12 July 1918, 74; Napsbury H50/A/01/025 Meeting, 22 January 1916. Between pp. 69-70, LMA.

184. Anon. "Happenings," United Methodist, 7 February 1916, 62; LCC LCC/MIN/00583 Meeting, 18 December 1917, 230 LMA.

185. BoC, letter and memorandum to superintendents, 9 July $1918 \mathrm{MH}$ 51/239 TNA.

186. LCC LCC/MIN/00580 Meeting, 29 June 1915, 615-16; LCC/MIN/00581 Meetings: 21 December 1915; 29 February 1916, 395-96 LMA.

187. LCC LCC/MIN/00581 Meeting, 30 May 1916, 626 LMA.

188. BoC, letter to MSs, 19 January $1918 \mathrm{MH}$ 51/239 TNA. 
189. BoC W/FM, 21 October 1914, 221 MH 50/43 TNA; BoC AR 1914, Part 2, Hull City Asylum 12 October 1914, 358.

190. BoC AR 1914, Part 2, Hants Asylum 6 November 1914, 234.

191. Home Office-(Class II.-Vote 4). Hansard HC Deb, 23 July 1913, vol. 55, cc. 2061-132; BoC, "Increased Annual Death Rate in Asylums," 15 January 1919 MH 51/239 TNA.

192. BoC W/FM 2 September 1914, 177 MH 50/43 TNA.

193. UK Lunacy Patients Admission Register 1846-1912, https://www.anc estry.co.uk/search/collections/uklunpatadmreg/.

194. Colney Hatch LCC/MIN/01003 Meetings: 20 November 1914, 169; 12 February 1915, 287 LMA.

195. Mercier, Organisation, 85-87; Lomax, Experiences, 114.

196. LCC LCC/MIN/00583 Meeting, 29 January 1918, 270 LMA.

197. Cobb Inquiry, Dr. Shaw Bolton 7 April 1922 Q:2842, MH 58/220 TNA.

198. Lomax, Experiences, 112-14.

199. Mercier, Organisation, 86-87; Lomax, Experiences, 114.

200. Colney Hatch $\mathrm{H} 12 / \mathrm{CH} / \mathrm{A} / 08 / 001$ Reports to sub-committee 17 May 1918, 57 LMA.

201. MACA, Herbert G, SA/MAC/G.3/9 WL.

202. Hanwell LCC/MIN/01096 Meeting, 29 January 1917, 297 LMA.

203. Hanwell LCC/MIN/01096 Meetings, 5 June 1916, 83; 29 January 1917, 297 LMA.

204. LCC LCC/MIN/00583 Meeting, 30 April 1918, 501-2 LMA.

205. Claybury LCC/MIN/00949 Meeting, 25 April 1918, 47-48 LMA.

206. Lomax, Experiences, 68.

207. Jones, “Culture": 24.

208. Office for National Statistics, Average Life Spans: Life Expectancy at Birth, Median Age at Death and Modal Age at Death, 1841 to 2010, England and Wales (undated), https://www.ons.gov.uk/ons/rel/mor tality-ageing/mortality-in-england-and-wales/average-life-span/chd-fig ure-1.xls; Colney Hatch $\mathrm{H12} / \mathrm{CH} / \mathrm{B} / 16 / 014$ Case notes of female patients who died in 1936-1937; $\mathrm{H12} / \mathrm{CH} / \mathrm{B} / 26 / 005$ Civil register of patients 1916-1917 LMA.

209. Colney Hatch LCC/MIN/01007 Meeting, 29 November 1918, 197 LMA.

210. Lomax, Experiences.

211. Hilton, Improving Psychiatric Care, 9, 11, 14.

212. BoC, "Orders for Destruction of Documents," 31 March $1909 \mathrm{MH}$ $51 / 723$ TNA. 
Open Access This chapter is licensed under the terms of the Creative Commons Attribution 4.0 International License (http://creativecommons.org/licenses/ by $/ 4.0 /$ ), which permits use, sharing, adaptation, distribution and reproduction in any medium or format, as long as you give appropriate credit to the original author(s) and the source, provide a link to the Creative Commons license and indicate if changes were made.

The images or other third party material in this chapter are included in the chapter's Creative Commons license, unless indicated otherwise in a credit line to the material. If material is not included in the chapter's Creative Commons license and your intended use is not permitted by statutory regulation or exceeds the permitted use, you will need to obtain permission directly from the copyright holder.

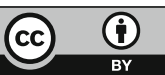

